\title{
Correction to: In situ silver nanoparticle synthesis on 3D-printed polylactic acid scaffolds for biomedical applications
}

\author{
Semilh Calamak ${ }^{1, a)}$ (D), Menekse Ermis ${ }^{2}$ \\ ${ }^{1}$ Department of Basic Pharmaceutical Sciences, Faculty of Pharmacy, Hacettepe University, Ankara 06100, Turkey \\ ${ }^{2}$ BIOMATEN, Middle East Technical University (METU) Center of Excellence in Biomaterials and Tissue Engineering, Ankara 06800, Turkey \\ a) Address all correspondence to this author. e-mail: semihcalamak@hacettepe.edu.tr \\ Published online: 7 April 2021
}

\section{Correction to:}

Journal of Materials Research volume 36, pages

166-175(2021)

https://doi.org/10.1557/s43578-020-00064-7

This article was updated to change the graphical abstract.

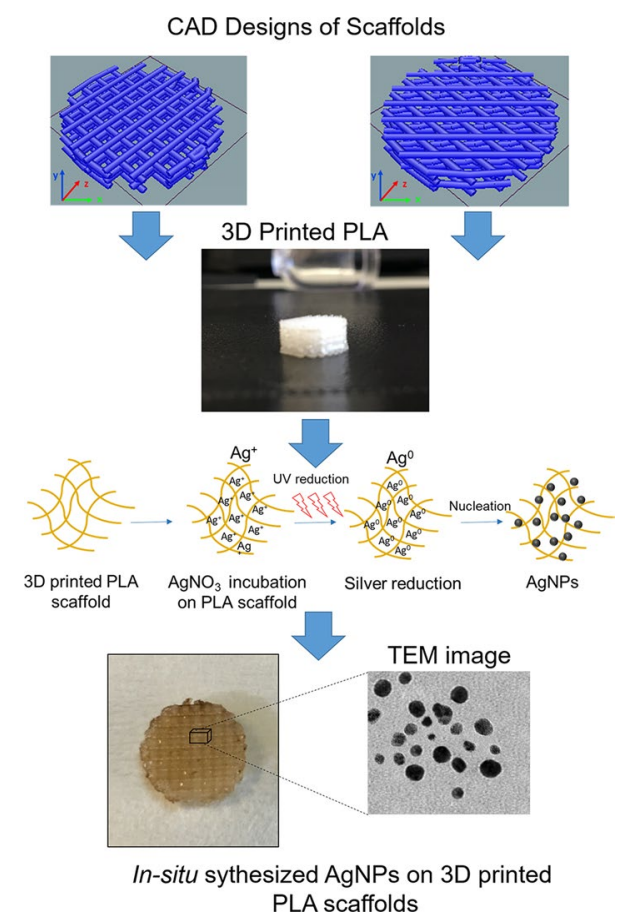

PLA scaffolds

The original article can be found online at https://doi.org/10.

1557/s43578-020-00064-7 